\title{
Nature of the Renal Injury following Total Renal Ischemia in Man
}

\author{
Bryan D. Myers, D. Craig Miller, John T. Mehigan, \\ Cornelius Olcott IV, Helen Golbetz, \\ Channing R. Robertson, Geri Derby, \\ Robin Spencer, and Stuart Friedman \\ Division of Nephrology, Departments of Medicine, Surgery and \\ Cardiovascular Surgery, and Chemical Engineering, Stanford \\ University Medical Center, Stanford, California 94305
}

A

bstract. The effects of total renal ischemia (TRI) of 15-87 min duration due to suprarenal clamping of the aorta were studied in 15 mannitol-treated patients undergoing abdominal aortic surgery. 15 patients undergoing similar surgery but requiring only infrarenal clamping served as controls. 1-2 h following TRI, GFR was reduced to only $39 \%$ of that in controls, $23 \pm 5$ vs. $59 \pm 7 \mathrm{ml} / \mathrm{min}(P<0.001)$. This could not be ascribed to impaired renal plasma flow (RPF), which was mildly reduced to $331 \pm 71$ and was not different from the value in controls, $407 \pm 66 \mathrm{ml} / \mathrm{min}$. However, impaired PAH extraction $(43 \pm 7 \%)$ and isosthenuria, not present in controls, suggest a primary role for tubular injury in lowering GFR at this time.

$24 \mathrm{~h}$ following TRI, the GFR remained depressed below controls, $45 \pm 8$ vs. $84 \pm 8 \mathrm{ml} / \mathrm{min}(P<0.005)$, while the transglomerular sieving of neutral dextrans was significantly enhanced (radius interval, 24-40 $\AA$ ). A theoretical analysis of transcapillary solute exchange revealed that these findings could be largely explained by a selective reduction of either RPF $(-61 \%)$ or of transmembrane hydraulic pressure difference $(-18 \%)$ below control values. Alternately, a combination of these two factors with changes of smaller magnitude could explain the findings. In contrast, a selective increase in oncotic pressure or decrease of the glomerular ultrafiltration coefficient could be excluded as a cause of hypofiltration $24 \mathrm{~h}$ after TRI. These observations lead us to suggest that the transient azotemia observed following TRI is due to a self-limited

Dr. Friedman's fellowship was supported by the Juvenile Diabetes Foundation.

Received for publication 24 May 1983 and in revised form 11 October 1983.

J. Clin. Invest.

(C) The American Society for Clinical Investigation, Inc.

0021-9738/84/02/0329/13 $\$ 1.00$

Volume 73, February 1984, 329-341 injury to the nephron that is identical to that seen in overt and sustained forms of acute renal failure.

\section{Introduction}

A variety of experimental animal models has been devised by investigators to simulate the hemodynamically mediated form of human acute renal failure (ARF). ${ }^{1}$ Most commonly, renal blood flow has been interrupted either mechanically or pharmacologically for 40-60 min. Transient but total renal ischemia (TRI) of this duration in the dog, rat, or rabbit is followed invariably by a lesion whose clinical manifestations, laboratory features, and pathology resemble closely those of human acute renal failure $(1,2)$. Micropuncture studies in vivo or perfusion of isolated renal tubules in vitro have revealed that an ensuing oliguria is attributable not only to a reduced glomerular filtration rate (GFR) but also to sequestration of tubule fluid within obstructed tubules, and to backleak of tubule fluid across necrotic epithelium into the interstitium $(1,3-6)$.

The application of a cross clamp to the suprarenal abdominal aorta for $\mathbf{4 0 ~ m i n ~ o r ~ l o n g e r ~ i n ~ m a n ~ i s ~ r e l a t i v e l y ~ c o m m o n p l a c e ~}$ during the course of operations to repair a diseased abdominal aorta. Despite the attendant TRI, postoperative ARF following abdominal aortic surgery is only common following emergency procedures to repair a ruptured aortic aneurysm $(7,8)$. Such patients, however, have frequently been hypovolemic and hypotensive before surgery and factors besides surgically induced TRI are likely to have been implicated in the pathogenesis of the ARF. In contrast, it has been estimated that $<10 \%$ of patients undergoing elective aortic surgery develop $\operatorname{ARF}(7,8)$. Of the reported cases, many have been subjected to infrarenal aortic surgical repair without recourse to a suprarenal cross clamp $(9,10)$.

1. Abbreviations used in this paper: ARF, acute renal failure; $r$, effective molecular radius; $\pi_{\mathrm{e}}$, efferent oncotic pressure; $K_{A v}$, fractional volume; GFR, glomerular filtration rate; $r_{0}$, mean glomerular pore radius; $\Delta P$, mean transcapillary hydraulic pressure difference; $\pi_{\mathrm{a}}$, afferent oncotic pressure; PAH, $p$-aminohippuric acid; RPF, renal plasma flow; TRI, total renal ischemia. 
The paucity of reported cases of ARF following elective occlusion of the suprarenal aorta in man may be due, in large part, to a uniform practice of infusing hypertonic mannitol before application of the abdominal aortic clamp (11). It is noteworthy that when TRI is used to induce ARF in experimental animals, the renal lesion can be attenuated by pretreatment with mannitol $(3,12-14)$. The modified renal lesion is qualitatively similar to, but milder than, that in unprotected forms of renal ischemic injury. In particular, experimental ARF modified by mannitol pretreatment is associated with high rather than low urine flow rates, and the normal impermeability of the tubule to filtration markers, such as inulin, is preserved (3, 12). We reasoned that if this is true also in mannitol-treated man, then it would be possible to use filtration markers and the clearance technique to characterize the effects of TRI on glomerular filtration and various tubule transport functions. In an effort to do this we combined a differential solute clearance technique with an evaluation of renal vasomotion in patients undergoing suprarenal aortic cross clamping. The purposes of the study were $(a)$ to determine whether suprarenal aortic clamping induces a renal injury in man that is overlooked or undetected and $(b)$ to compare the pathophysiology of such renal injury with that in overt human ARF and in animal models of ARF induced by TRI.

\section{Methods}

\section{Patient population}

15 patients requiring suprarenal aortic cross clamping to affect surgical repair of the abdominal aorta comprised the experimental population. In five patients, surgery was undertaken to resect an abdominal aortic aneurysm that extended up to or above the level of the renal arteries. The remainder had exuberant aortic atheroma that threatened the patency of either the aorta per se or the origins of the renal, mesenteric, or lower limb circulations. A second group of 15 patients undergoing infrarenal aortic surgical repair to resect an aneurysm $(n=8)$ or to bypass occlusive aortoiliac atheroma $(n=7)$ served as control subjects. In these latter subjects, the aorta was cross clamped below the level of the renal arteries.

Age was similar, $62 \pm 9$ vs. $65 \pm 9 \mathrm{yr}$, respectively, (mean $\pm 1 \mathrm{SD}$ ) and males predominated in both the experimental and control groups. Judged by a serum creatinine level that was uniformly $<2 \mathrm{mg} / \mathrm{dl}$, preoperative renal function was adequate in all 30 patients. Previously diagnosed and treated hypertension, however, was more common in the experimental (suprarenal) than the control (infrarenal) group. A history of hypertension was obtained in seven members of the experimental group, possibly reflecting renovascular disease, but in only three of the control group. A study protocol, approved previously by the Committee on the Use of Human Subjects in Research at Stanford University, was presented and explained to each patient on the day before surgery. Signed consent to participate in the study was obtained in each instance.

\section{Operative management}

Anesthesia was maintained in all cases with either ethrane or halothane. Estimated blood losses were replaced with whole blood. However, crystalloid solutions (normal saline or $5 \%$ dextrose) were infused at a rate estimated to exceed other operative fluid losses. Judged by a measured elevation of central venous pressure by $2-10 \mathrm{mmHg}$ above initial levels and a reduction of intraoperative hematocrit to values $\sim 12-16 \%$ below preoperative levels, plasma volume expansion and hemodilution were achieved in every patient. An intravenous bolus injection of $12.5 \mathrm{~g}$ mannitol as a hypertonic $20 \%$ solution was administered shortly after induction of anesthesia and thereafter at hourly intervals until the aortic cross-clamp was applied. Thus, all patients received between 12.5 and $37.5 \mathrm{~g}$ of hypertonic mannitol, depending on the time required to prepare the surgical field for aortic cross clamping. All patients also received an infusion of sodium nitroprusside at $0.5-3.0 \mu \mathrm{g} / \mathrm{kg}$ per min as needed to prevent mean arterial pressure from rising $>100 \mathrm{mmHg}$ during the surgery.

In control subjects, direct sharp and blunt dissection was used to expose the abdominal aorta immediately below the left renal vein. After appropriate distal dissection either in the abdomen or in the femoral triangle, the patient received systemic heparin. At this time, distal DeBakey vascular clamps or Hydro-Grip vascular clamps (Fogarty Mfg. Co., Dayton, $\mathrm{OH}$ ) were applied to the iliac or femoral arteries. The proximal cross clamp was then applied to the aorta just below the renal arteries. In the experimental group, the suprarenal abdominal aorta was dissected free from below. Frequently, the dissection included the superior mesenteric artery and celiac axis. After distal dissection, heparinization, and application of distal clamps to the iliac or femoral arteries, a DeBakeystyle vascular clamp was applied to the aorta either between the superior mesenteric and the renal arteries or above the celiac axis. The diseased aorta was then resected and replaced with an appropriate tube or bifurcation graft. In cases where the origins of the renal or mesenteric arteries were partially occluded, reconstruction or endarterectomy was performed and the affected vessel reimplanted into the aortic graft. Unclamping was carried out after flushing any particulate debris and all air from the graft and aorta. The duration of TRI induced by the suprarenal aortic cross clamp in the experimental group averaged $44 \pm 23$ min (range 15-87 $\mathrm{min}$ ). The experimental group also differed from the control group in that the total duration of surgery tended to be longer, $322 \pm 63$ vs. $268 \pm 58$ min (mean $\pm 1 \mathrm{SD}$ ), respectively.

\section{Study protocol}

The determination of GFR and several of its determinants was performed on the day preceding surgery, throughout the surgery and on the day following surgery.

Preoperative. No patient was catheterized on the preoperative day so that all base-line (preoperative) studies were performed with the patient voiding spontaneously during a state of diuresis that was established by oral water loading. In 12 elderly males with symptoms consistent with partial obstruction of the bladder neck, a timed 24-h urine collection was made and the clearance of endogenous creatinine was used as a measure of GFR. In the remaining 18 patients, three carefully timed 20-30-min urine collections were made during a constant infusion of inulin, and GFR was expressed as the mean value of the individual inulin clearances.

Intraoperative. Immediately after anesthesia was induced, each patient was catheterized with an indwelling bladder catheter and a priming intravenous injection of inulin $(50 \mathrm{mg} / \mathrm{kg})$ and $p$-aminohippuric acid (PAH, $6 \mathrm{mg} / \mathrm{kg}$ ) was administered. Inulin and PAH were then infused continuously at a rate calculated to maintain plasma levels constant at 20 and $1.5 \mathrm{mg} / \mathrm{dl}$, respectively. In control subjects (infrarenal clamping), the infusion rate of the clearance markers was held constant throughout surgery. In experimental subjects the infusion was discontinued when the suprarenal aorta was clamped and resumed at half the initial rate when the aorta was unclamped. After an initial 40-min equilibration period, consecutive 20-30-min urine collections were made throughout 
the course of the surgery. Arterial blood was drawn from a radial arterial line to bracket each urine collection.

To determine the renal extraction of PAH and inulin, renal venous and radial arterial plasma were simultaneously sampled immediately before application and again 30 to $60 \mathrm{~min}$ after release of the aortic cross clamp. In 11 patients undergoing suprarenal cross clamping, renal blood flow was also determined at these same two times using a precalibrated electromagnetic blood flow meter (601D, Carolina Medical Electronics, King, NC). To accomplish this, snugly fitting flow probes were placed around each main renal artery and in some cases around a single large accessory vessel. Each determination was performed in triplicate and renal blood flow was expressed as the sum of the measured flows in the individual renal arteries. Inadequate exposure of the renal arteries prevented determination of renal blood flow by this method in patients undergoing infrarenal cross clamping. Radial arterial pressure was monitored via a saline-filled catheter connected to a pressure transducer (model HP 1280; Hewlett-Packard Co., Palo Alto, CA) at the beginning and end of each urine collection period. Plasma oncotic pressure, measured directly with a membrane osmometer (Weil oncometer 196, Instrumentation Laboratory, Inc. Lexington, MA) and arterial hematocrit were determined serially during the preclamp, intraclamp, and postclamp periods.

GFR was equated with the inulin clearance, which was calculated as:

$$
\mathrm{C}_{\text {in }}=\mathrm{U}_{\text {in }} V / \mathrm{P}_{\text {in }},
$$

where $C_{i n}, U_{i n}$, and $P_{\text {in }}$ are the clearance of inulin, and urine and plasma inulin concentrations, respectively, and $V$ is the urine flow rate.

Renal plasma flow (RPF) was calculated using the equation

$$
\mathrm{RPF}=\mathrm{C}_{\mathrm{PAH}} / \mathrm{E}_{\mathrm{PAH}},
$$

where $C_{P A H}$ is the clearance of PAH and $E_{P A H}$ is the renal extraction of PAH, i.e., the arterial plasma PAH concentration minus the renal venous plasma PAH concentration divided by the arterial PAH concentration.

Renal blood flow was calculated by dividing calculated RPF by ( 1 - hematocrit), where the hematocrit is expressed in its fractional form. Fractional sodium excretion, $\mathrm{FE}_{\mathrm{Na}}$, was expressed as the fractional sodium clearance multiplied by 100 .

Postoperative. All clearance measurements together with determination of mean arterial pressure, plasma oncotic pressure, and arterial hematocrit were repeated on the first postoperative day. The postoperative clearance protocol differed from that used intraoperatively only in that a polydisperse preparation of dextran 40 (rheomacrodex, Pharmacia Fine Chemicals, AB Uppsala, Sweden) was administered in a dose of $130 \mathrm{mg} / \mathrm{kg}$ by slow intravenous injection immediately after the inulin/ PAH prime. At the end of a 40-60-min equilibration period, three carefully timed 20-30-min urine collections were made to permit determination of the postoperative inulin and PAH clearances. From urine obtained during the first of these timed collections, fractional clearances of dextran $\left(\theta_{\mathrm{D}}\right)$ were computed using the equation

$$
\theta_{\mathrm{D}}=(\mathrm{U} / \mathrm{P})_{\mathrm{D}} /(\mathrm{U} / \mathrm{P})_{\text {in }},
$$

where $(\mathrm{U} / \mathrm{P})_{\mathrm{D}}$ and $(\mathrm{U} / \mathrm{P})_{\text {in }}$ refer to the urine-to-midpoint plasma concentration ratios of dextran and inulin, respectively.

\section{Laboratory methods}

For the calculation of GFR, inulin concentration of urine and plasma was determined by the autoanalyzer method of Fjeldbo and Stamey (15). This method uses the fructose-specific reagent resorcinol and is uninfluenced by the presence of mannitol and dextran. The autoanalyzer method of Harvey and Brothers (16) was used for the determination of PAH.

Separation of dextran $\mathbf{4 0}$ and inulin in plasma and urine into narrow fractions $(\sim 2 \AA)$ was accomplished by gel permeation chromatography using precalibrated columns packed with sephacryl S200 (Pharmacia Fine Chemicals) (17). Two columns, 93 and $96 \mathrm{~cm}$ in length with internal diameters of $1.6 \mathrm{~cm}$, were used. With $0.3 \%$ buffered saline as eluent, 2.6-ml eluted fractions were collected with an automatic fractionator (model S-80; Gilson Medical Electronics, Inc., Middleton, WI). The void volume was determined with blue dextran and the fractional volume available to the solute $\left(\mathrm{K}_{\mathrm{Av}}\right)$ was calculated as

$$
\mathrm{K}_{\mathrm{AV}}=\left(V_{\mathrm{e}}-V_{0}\right) /\left(V_{\mathrm{t}}-V_{0}\right),
$$

where $V_{\mathrm{e}}$ is the elution volume of the solute and $V_{\mathrm{t}}$ the total volume of the gel column (18). Effective molecular radii ( $r$ ) for individual dextran fractions were calculated from $K_{A v}$ (19). After gel permeation chromatography of plasma and urine, eluted fractions were assayed for dextran and inulin concentrations by using a modification of the autoanalyzer anthrone method of Scott and Melvin (20). Although inulin, dextran, and mannitol are all anthrone positive, cross reactivity was not encountered because of the differing elution volumes of each solute. The urine-to-plasma concentration ratio of the two peak inulin fractions was used for subsequent determinations of fractional clearances. It should be noted that this ratio, as determined by the anthrone method, was not significantly different from that obtained by the resorcinol method.

Plasma and urinary creatinine levels were determined by a ratedependent modification of the Jaffe reaction using a creatinine analyzer (Beckman Instruments, Inc., Fullerton, CA) (21). This method minimizes the influence of slow reacting, noncreatinine plasma chromogens and thus provides an estimate of true creatinine concentration.

\section{Theoretical analysis of glomerular transcapillary solute exchange}

In the normal kidney, inulin and dextran are excreted by glomerular filtration and neither secreted nor reabsorbed by the tubule (22). The same appears to hold true for the kidney subjected to TRI of moderate duration when pretreatment with mannitol has been administered before application of the ischemic insult $(3,12)$. Under these conditions the urinary clearance of a dextran of given size relative to that of inulin reflects its Bowman's space fluid-to-plasma water concentration ratio. This ratio, known as a sieving coefficient, provides a measure of the extent to which the glomerular capillary wall restricts a dextran macromolecule of given size. Theoretical analysis of the molecular sieving behavior of the glomerulus in nonproteinuric states indicates that the glomerular capillary wall behaves, to good approximation, as an isoporous filter (23). The sieving coefficient of a neutral dextran of given size, however, is not solely dependent on glomerular pore size. Rather, it is important to recognize that solute and water transport across the glomerular capillary are closely coupled. In general, the sieving coefficient for a given neutral macromolecule depends inversely on the GFR. Accordingly, the filtration of macromolecules will be influenced not only by intrinsic properties of the glomerular capillary wall, but also by the determinants of GFR (23).

The quantities that determine GFR are renal plasma flow, afferent oncotic pressure $\left(\pi_{\mathrm{a}}\right)$, the mean transcapillary hydraulic pressure difference $(\Delta P)$, and the glomerular ultrafiltration coefficient $\left(\mathrm{K}_{f}\right)$, which is defined here as the product of effective hydraulic permeability and total glomerular capillary surface area in the two kidneys (24). Because $\Delta P$ cannot be determined in man, we selected two values ( 30 and $40 \mathrm{mmHg}$ ) that should bracket the actual value, and the lower of which slightly 
exceeds that of the calculated oncotic pressure at the efferent end of the glomerular capillary network (25). The membrane parameters $K_{f}$ and mean glomerular pore radius $\left(r_{0}\right)$ for the control population were then calculated. To determine $\mathrm{K}_{f}$, the assigned $\Delta \mathrm{P}$ values together with the mean values of GFR, renal plasma flow, and $\pi_{\mathrm{a}}$ measured in control subjects were applied to the ultrafiltration model of Deen et al. (24). To determine $r_{0}$ the same values together with the control fractional dextran clearances were analyzed with a model of solute transport that treats the glomerular capillary wall as an isoporous membrane (23).

The foregoing models of ultrafiltration (24) and of solute transport through an isoporous membrane (23) were next used to examine the pathogenesis of glomerular hypofiltration following TRI. To do this, the aforementioned values measured in or assigned to control subjects were used as base values around which selective perturbations were made. The selective perturbation of each determinant required to explain the observed reduction of GFR in post-TRI patients was calculated (24). Thereafter, the predicted effect of each selective perturbation on the control fractional dextran clearance profile was determined (23). In making the latter determination, the remaining values for GFR determinants and $r_{0}$ were those of the control population, and were held constant. By assuming that $r_{0}$ does not change following TRI, it becomes possible to compute the magnitude of any selective change in RPF, $\Delta P$, $\pi_{\mathrm{a}}$, and $K_{f}$, that is required to explain both the measured differences in transglomerular water (GFR) and solute flux (fractional dextran clearances) in the two populations.

\section{Statistical analysis}

The significance of observed differences between the experimental and control groups was analyzed using the $t$ test for unpaired data. Differences within the experimental group at different times during surgery were evaluated by the $t$ test for paired data. All results are expressed as the mean \pm SEM.

\section{Results}

\section{Preoperative findings (Table I)}

The preoperative GFR was at the lower end of the range predicted for healthy subjects in their sixth to eight decades in both control and experimental groups (26). The mean values of $72 \pm 7$ and $68 \pm 7 \mathrm{ml} / \mathrm{min}$ per $1.73 \mathrm{~m}^{2}$, respectively, did not differ significantly between the two populations. Mean values for mean arterial pressure, hematocrit, plasma oncotic pressure, and plasma protein concentration were also within normal limits and are summarized in Table I.

Table I. Preoperative Findings

\begin{tabular}{lccc}
\hline & $\begin{array}{l}\text { Control group } \\
\text { (infrarenal) }\end{array}$ & $\begin{array}{l}\text { Experimental group } \\
\text { (suprarenal) }\end{array}$ & $P$ value \\
\hline $\begin{array}{l}\text { GFR }\left(\mathrm{ml} / \mathrm{min} \text { per } 1.73 \mathrm{~m}^{2}\right) \\
\begin{array}{l}\text { Mean arterial pressure } \\
(\mathrm{mmHg})\end{array}\end{array}$ & $72 \pm 7$ & $68 \pm 7$ & $\mathrm{NS}$ \\
$\begin{array}{l}\pi_{\mathrm{a}}(\mathrm{mmHg}) \\
\text { Plasma protein concen- }\end{array}$ & $100 \pm 4$ & $109 \pm 4$ & $\mathrm{NS}$ \\
$\quad$ tration $(\mathrm{g} / \mathrm{dl})$ & $24.2 \pm 0.8$ & $25.6 \pm 0.9$ & $\mathrm{NS}$ \\
$\begin{array}{l}\text { Hematocrit }(\%) \\
\text { Hem }\end{array}$ & $7.1 \pm 0.2$ & $7.2 \pm 0.2$ & $\mathrm{NS}$ \\
& $42 \pm 1$ & $38 \pm 1$ & $\mathrm{NS}$ \\
\hline
\end{tabular}

\section{Effects of abdominal aortic surgery}

An attempt was made to monitor the intraoperative GFR by determining the urinary clearance of inulin at 20-30-min intervals throughout the course of surgery. This was made difficult by a tendency for inulin clearance in both experimental and control populations to decline progressively, and sometimes precipitously, before application of the aortic cross clamp. The difficulty was compounded by wide fluctuations in the rate of urine flow in 11 patients in whom one or more episodes of oligoanuria were followed by polyuria. With oligoanuria the rate of inulin excretion fell below the infusion rate while the opposite occurred during the subsequent period of polyuria. This finding suggests that filtered inulin was alternately sequestered within and then washed out from the urinary dead space (27). In an effort to eliminate this artifact and to define the spontaneous variations of GFR, an inulin clearance vs. time plot for each patient and control was subjected to a curvesmoothing technique (28). ${ }^{2}$

The time-weighted GFR values (expressed as a percentage of the preoperative value) were then extrapolated from individual curves and averaged in each population for two 2-h periods following induction of anesthesia, but preceeding cross clamping, and that following application of the cross clamp, respectively. This idealized representation is depicted in Fig. 1 and suggests that GFR in the experimental group declined substantially during the 2 nd $h$ of surgery, a period during which the upper abdominal aorta and renal pedicles were being manipulated. However, the disparity in GFR between the experimental and control groups grew even wider and achieved statistical significance after release of the aortic cross clamp.

Some hemodynamic effects of aortic surgery are summarized in Table II. Mean arterial pressure and heart rate did not differ in the two groups and remained in a normal range throughout

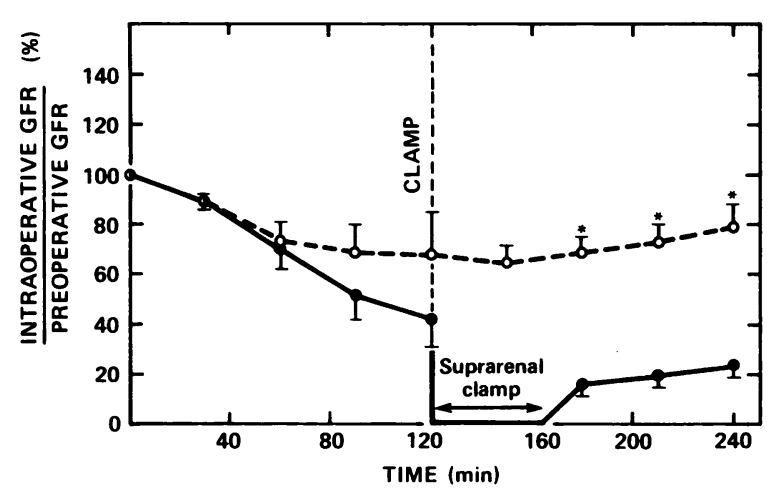

Figure 1. Idealized percent GFR vs. time curves before and following suprarenal $(\bullet)$ and infrarenal $(O)$ aortic clamping in patients undergoing abdominal aortic surgical repair. ${ }^{*}, P<0.001$.

2. The curve-smoothing technique used here is based on a nonlinear algorithm that uses running means, running medians, and quadratic interpolation to transform the data points and integrals (28). 
Table II. Hemodynamic Findings during Aortic Surgery

\begin{tabular}{|c|c|c|c|c|c|c|}
\hline & \multicolumn{3}{|c|}{ Infrarenal clamp $(n=15)$} & \multicolumn{3}{|c|}{ Suprarenal clamp* $(n=15)$} \\
\hline & Pre & Intra & Post & Pre & Intra & Post \\
\hline Mean arterial pressure $(\mathrm{mmHg})$ & $83 \pm 3$ & $79 \pm 3$ & $82 \pm 2$ & $92 \pm 5$ & $82 \pm 4$ & $87 \pm 4$ \\
\hline Heart rate $($ beats $/ \mathrm{min})$ & $73 \pm 3$ & $78 \pm 4$ & $85 \pm 4$ & $73 \pm 6$ & $75 \pm 4$ & $81 \pm 4$ \\
\hline Hematocrit $(\%)$ & $35 \pm 1$ & $36 \pm 2$ & $35 \pm 2$ & $34 \pm 1$ & $33 \pm 1$ & $34 \pm 1$ \\
\hline Plasma protein $(g / d l)$ & $5.1 \pm 0.2$ & $5.0 \pm 0.1$ & $4.6 \pm 0.2$ & $5.4 \pm 0.1$ & $4.6 \pm 0.2$ & $5.4 \pm 0.2$ \\
\hline RBF (calculated) (ml/min per $\left.1.73 \mathrm{~m}^{2}\right)$ & $391 \pm 80$ & $436 \pm 80$ & $541 \pm 84$ & $327 \pm 59$ & - & $500 \pm 109$ \\
\hline
\end{tabular}

* None of listed values are significantly different from corresponding values in control (infrarenal) subjects.

surgery. Judged by a comparable average reduction in hematocrit between 33 and $36 \%$, and in plasma protein concentration between 4.6 and $5.4 \mathrm{~g} / 100 \mathrm{ml}$, both groups were similarly volumeexpanded. Notwithstanding volume expansion, however, renal blood flow was depressed. When calculated from the urinary clearance and renal extraction of $\mathrm{PAH}$, renal blood flow averaged $391 \pm 80,436 \pm 80$, and $541 \pm 84 \mathrm{ml} / \mathrm{min}$ per $1.73 \mathrm{~m}^{2}$ before, during, and after infrarenal aortic clamping, respectively, in the control group. Corresponding values in the experimental group before and after removal of the clamp, 327 \pm 59 and $500 \pm 109$ $\mathrm{ml} / \mathrm{min}$ per $1.73 \mathrm{~m}^{2}$, respectively, were not significantly different from those in the control group. Because of uncertainty regarding the reliability of PAH as an indicator of renal blood flow in the presence of low extraction ratios (29), renal blood flow was measured directly with an electromagnetic blood flowmeter in 11 members of the experimental group (Fig. 2). It should be emphasized that these measurements represent instantaneous determinations of blood flow at a single point in time, whereas the PAH method reflects cumulative blood flow throughout the preclamp and postclamp period. Nevertheless, measurements of instantaneous renal blood flow were in good agreement with those obtained from the renal clearance and extraction of PAH, averaging $330 \pm 77 \mathrm{ml} / \mathrm{min}$ per $1.73 \mathrm{~m}^{2}$ before application and $474 \pm 65 \mathrm{ml} / \mathrm{min}$ per $1.73 \mathrm{~m}^{2}$ following removal of the clamp. When taken together, these findings suggest that on average renal blood flow was depressed to $<50 \%$ of predicted normal values during surgical preparation of the abdominal aorta for cross clamping (26). Regardless of whether the aorta was clamped above or below the renal arteries, however, renal blood flow tended to increase by $\sim 40-50 \%$ following release of the clamp. Thus, suprarenal aortic clamping had opposite effects on renal blood flow and inulin clearance with the former tending to increase (Fig. 2) while the latter declined (Fig. 1) following unclamping.

\section{Effects of total renal ischemia}

Early changes $(\sim 2 h)$. The early post-TRI period in this study was defined as commencing $30 \mathrm{~min}$ after release of the aortic cross clamp and terminating at the end of surgery. The corresponding period following release of the infrarenal clamp in control subjects was used for comparison. The results in the two groups are compared in Table III. RPF was similarly reduced in post-TRI and control subjects averaging $331 \pm 71$ vs. $407 \pm 66$ $\mathrm{ml} / \mathrm{min}$ per $1.73 \mathrm{~m}^{2}$, respectively. GFR in post-TRI patients by contrast, was disproportionately depressed to a value corresponding to only $39 \%$ of that in control subjects $23 \pm 5$ vs. $59 \pm 7$ $\mathrm{ml} / \mathrm{min}$ per $1.73 \mathrm{~m}^{2}(P<0.001)$. Because the urinary clearance of inulin may not be a reliable measure of GFR in the face of fluctuating rates of urinary flow, we also determined the renal inulin extraction ratio in each population. This ratio in postTRI patients measured $46 \%$ of that in control subjects, $6 \pm 1$ vs. $13 \pm 2 \%(P<0.005)$. Thus, if RPF was indeed similar in the two populations, the lower renal inulin extraction ratio indicates a greater than twofold depression of GFR following suprarenal compared with that following infrarenal clamping. Afferent (systemic) oncotic pressure was reduced to $\sim 60 \%$ of preoperative levels and was not different in the two groups, averaging 14.6 \pm 0.8 and $14.3 \pm 0.7 \mathrm{mmHg}$, respectively.



Figure 2. Instantaneous renal blood flow measured with an electromagnetic flow probe before suprarenal clamping (pre) and 30-60 min after unclamping (post). 
Table III. Intraoperative (Postclamp) Findings

\begin{tabular}{|c|c|c|c|}
\hline & $\begin{array}{l}\text { Control } \\
\text { group } \\
\text { (infrarenal) }\end{array}$ & $\begin{array}{l}\text { Experimental group } \\
\text { (suprarenal) }\end{array}$ & $P$ value \\
\hline \multicolumn{4}{|l|}{$\mathrm{RPF}(\mathrm{ml} / \mathrm{min} \mathrm{per}$} \\
\hline $\left.1.73 \mathrm{~m}^{2}\right)$ & $407 \pm 66$ & $331 \pm 71$ & NS \\
\hline \multicolumn{4}{|l|}{ GFR $(\mathrm{ml} / \mathrm{min} \mathrm{per}$} \\
\hline $\left.1.73 \mathrm{~m}^{2}\right)$ & $59 \pm 7$ & $23 \pm 5$ & $<0.001$ \\
\hline \multicolumn{4}{|l|}{ Inulin extraction } \\
\hline ratio $(\%)$ & $13 \pm 2$ & $6 \pm 1$ & $<0.005$ \\
\hline$\pi_{\mathrm{a}}(m m H g)$ & $14.3 \pm 0.7$ & $14.6 \pm 0.8$ & NS \\
\hline $\begin{array}{l}\text { Urine flow rate } \\
(\mathrm{ml} / \mathrm{min})\end{array}$ & \multicolumn{2}{|c|}{ Urine flow rate } & NS \\
\hline $\begin{array}{c}\text { Urine/plasma } \\
\text { osmolality }\end{array}$ & $1.42 \pm 0.09$ & $1.15 \pm 0.05$ & $<0.02$ \\
\hline $\begin{array}{l}\text { Urine/plasma } \\
\text { inulin }\end{array}$ & $29 \pm 6$ & $14 \pm 4$ & $<0.025$ \\
\hline $\begin{array}{c}\text { Fractional sodiun } \\
\text { excretion (\%) }\end{array}$ & $3.8 \pm 1.9$ & $13.0 \pm 4.2$ & NS \\
\hline $\begin{array}{l}\text { PAH extraction } \\
\text { ratio }(\%)\end{array}$ & $69 \pm 4$ & $43 \pm 7$ & $<0.005$ \\
\hline
\end{tabular}

Although urine flow was similar following either suprarenal or infrarenal clamping $(3.3 \pm 1.1 \mathrm{vs.} 3.2 \pm 0.8 \mathrm{ml} / \mathrm{min})$, there was clear evidence of proximal tubule dysfunction in post-TRI patients relative to controls. Thus, PAH extraction (43 \pm 7 vs. $69 \pm 4 \%, P<0.005$ ) was significantly impaired following TRI. There was also a reduced urine-to-plasma osmolality $(1.15 \pm 0.05$ vs. $1.42 \pm .09, P<0.02)$ and urine-to-plasma inulin concentration (14 \pm 4 vs. $29 \pm 6, P<0.025$ ), while the fractional excretion of sodium was increased threefold $(13.0 \% \pm 4.2 \%$ vs. $3.8 \% \pm 1.9 \%)$ following TRI. These latter findings are consistent with a distal tubular injury manifested by reduced ability to concentrate the urine and to reabsorb filtered water and sodium in the wake of TRI. However, since mannitol is likely to have been sequestered in the kidneys during suprarenal clamping, it is possible that the findings reflect a mannitol-induced osmotic diuresis rather than intrinsic distal tubular injury per se.

Anuria persisting for $20 \mathrm{~min}$ or longer was never encountered in controls after release of the infrarenal clamp, but was observed in six patients of the experimental group immediately after release of the suprarenal clamp (Table IV). Instantaneous plasma flow was easily measurable with an electromagnetic blood flow meter and reduced by no more than $50-60 \%$ below predicted normal values during four of these anuric episodes (range, 198$227 \mathrm{ml} / \mathrm{min}$ ). In contrast, the renal arteriovenous inulin concentration difference was so low as to be close to or within the range or error of our assay in five instances with the result that renal inulin extraction and presumably, the rate of glomerular ultrafiltration were negligible during these five episodes of anuria. A parallel decline in the PAH extraction ratio (Table IV) suggests that anuria following TRI was accompanied also by a proximal tubular injury. Nevertheless, PAH extraction, albeit reduced, was easily measurable and attests to the persistence of renal perfusion in each anuric patient following TRI. These findings suggest that TRI in man is not followed by a "no-reflow" phenomenon and that anuria is a consequence of a reduced glomerular transcapillary hydraulic pressure difference, a lower $K_{f}$, transtubular backleak of filtrate, or some combination of these factors.

Late findings (24-h, Table $V$ ). The post-TRI experimental and control subject groups were similarly volume expanded at the time of study on the first postoperative day. Body weight was increased above preoperative values by $6.8 \pm 1.1$ and $6.7 \pm 0.7 \%$, respectively. Hematocrit $(37 \pm 1 \%)$ and plasma protein concentration $(5.2 \pm 0.1 \mathrm{~g} / \mathrm{dl})$ in post-TRI patients were similar to corresponding values in control subjects $(39 \pm 1 \%$ and $5.4 \pm 0.2$ $\mathrm{g} / \mathrm{dl}$, respectively), with both quantities tending to be reduced below the preoperative values provided in Table I. Mean arterial pressure during the postoperative study was in the normal range, averaging $96 \pm 4$ and $95 \pm 4 \mathrm{mmHg}$ in post-TRI patients and control subjects, respectively.

In keeping with the volume-expanded state, GFR in control subjects was elevated into a range somewhat higher than observed preoperatively and averaging $84 \pm 8 \mathrm{ml} / \mathrm{min}$ per $1.73 \mathrm{~m}^{2}$. GFR in post-TRI patients, however, remained significantly depressed at $45 \pm 8 \mathrm{ml} / \mathrm{min}$ per $1.73 \mathrm{~m}^{2}$, only $54 \%$ of that in control subjects $(P<0.005)$. The differences in GFR could not be ascribed to plasma oncotic pressure, which was similarly lowered in both experimental and control populations to $16.4 \pm 0.4$ and $17.7 \pm 0.7$ $\mathrm{mmHg}$, respectively $(P=\mathrm{NS})$. The PAH clearance in post-TRI patients was also only half that in control subjects, $200 \pm 31$ vs. $397 \pm 51 \mathrm{ml} / \mathrm{min}$ per $1.73 \mathrm{~m}^{2}(P<0.005)$. In the absence of measurements of PAH extraction at this time, however, it is not known whether this difference in PAH clearance reflects a late reduction in renal plasma flow following TRI.

Urine flow in post-TRI patients was similar to that in control subjects averaging $1.9 \pm 0.3$ and $1.8 \pm 0.5 \mathrm{ml} / \mathrm{min}$, respectively. However, concentrating ability (urine-to-plasma osmolality

Table IV. Features of Postclamp Anuria

\begin{tabular}{lllll}
\hline Patient & Duration & $\mathrm{E}_{\text {inulin }}{ }^{*}$ & $\mathrm{RPE}_{\mathbf{M}} \neq$ & $\mathrm{E}_{\mathbf{P A H}}{ }^{*}$ \\
\hline No. & $\min$ & $\%$ & $\mathrm{ml} / \mathrm{min}$ & $\%$ \\
1 & 20 & 11 & 198 & 79 \\
2 & 30 & 4 & 216 & 51 \\
3 & 94 & 2 & - & 24 \\
4 & 28 & 2 & 227 & 28 \\
5 & 36 & 3 & 217 & 23 \\
6 & 20 & 3 & - & 13 \\
& & & &
\end{tabular}

* $E$ is the extraction ratio calculated as ([RA] - [RV])/[RA], where $[R V]$ and $[R A]$ are the renal venous and arterial solute concentrations.

$\ddagger \mathrm{RPF}_{\mathrm{M}}$ is the renal plasma flow measured with an electromagnetic blood flow meter and corrected for hematocrit. 
$=1.5 \pm 0.1$ vs. $1.9 \pm 0.1)$, fractional sodium reabsorption $\left(\mathrm{FE}_{\mathrm{Na}}\right.$ $=5.0 \pm 1.9$ vs. $1.3 \pm 0.4 \%)$, and fractional water reabsorption $(\mathrm{U} /$ $P$ inulin $=39 \pm 8$ vs. $68 \pm 9$ ) remained depressed in post-TRI patients relative to control subjects, although only the difference in the last urinary index reached statistical significance (Table V). The numerical differences in the foregoing urinary indices are consistent with persisting distal tubular dysfunction $24 \mathrm{~h}$ after TRI.

The extent to which postoperative GFR was depressed below preoperative values in individual post-TRI patients is plotted as a function of suprarenal aortic clamp time in Fig. 3. In keeping with findings in experimental animals, no postoperative GFR reduction was observed in three patients subjected to TRI of $<20$ min duration (1). Four of five patients in whom the duration of TRI was 50 min or longer, however, had the greatest degree of postoperative GFR depression observed. Linear regression analysis of the relationship between postoperative GFR reduction and the duration of TRI revealed a correlation coefficient of $-0.54(P<0.05)$.

Given the variability of GFR depression among post-TRI patients (Fig. 3), it is not surprising that the extent of tubular injury and the postoperative course varied considerably among patients. Linear regression analysis of postoperative (24-h) urinary indices of tubule function and GFR revealed both urineto-plasma osmolality and urine-to-plasma inulin to be directly related to GFR, the correlation coefficients being 0.85 and 0.86 , respectively. Conversely, a weaker relationship between $\mathrm{FE}_{\mathrm{Na}}$ and GFR (correlation coefficient $=-0.46$ ) was inverse. Thus, the magnitude of distal tubular dysfunction following TRI appeared to parallel the extent to which postoperative GFR was depressed. The average peak postoperative serum creatinine level in post-TRI patients was higher than the preoperative level, $2.3 \pm 0.4$ vs. $1.3 \pm 0.1 \mathrm{mg} / \mathrm{dl}$, respectively. This occurred largely

Table V. Postoperative Findings

\begin{tabular}{|c|c|c|c|}
\hline & $\begin{array}{l}\text { Control group } \\
\text { (infrarenal) }\end{array}$ & $\begin{array}{l}\text { Experimental group } \\
\text { (suprarenal) }\end{array}$ & $P$ value \\
\hline$\Delta$ weight $(\%)$ & $6.7 \pm 0.7$ & $6.8 \pm 1.1$ & NS \\
\hline Hematocrit (\%) & $39 \pm 1$ & $37 \pm 1$ & NS \\
\hline $\begin{array}{l}\text { Plasma protein concen- } \\
\text { tration }(g / d l)\end{array}$ & $5.4 \pm 0.2$ & $5.2 \pm 0.1$ & NS \\
\hline $\begin{array}{l}\text { Mean arterial pressure } \\
(g / d l)\end{array}$ & $95 \pm 4$ & $96 \pm 4$ & NS \\
\hline $\begin{array}{l}\text { GFR }(\mathrm{ml} / \mathrm{min} \text { per } \\
\left.1.73 \mathrm{~m}^{2}\right)\end{array}$ & $84 \pm 8$ & $45 \pm 8$ & $<0.005$ \\
\hline $\begin{array}{l}\text { PAH clearance }(\mathrm{ml} / \mathrm{min} \\
\left.\text { per } 1.73 \mathrm{~m}^{2}\right)\end{array}$ & $397 \pm 51$ & $200 \pm 31$ & $<0.005$ \\
\hline$\pi_{\mathrm{a}}(m m H g)$ & $17.7 \pm 0.7$ & $16.4 \pm 0.4$ & NS \\
\hline Urine flow rate $(\mathrm{ml} / \mathrm{min})$ & $1.8 \pm 0.5$ & $1.9 \pm 0.3$ & NS \\
\hline Urine/plasma osmolality & $1.9 \pm 0.1$ & $1.5 \pm 0.1$ & NS \\
\hline Urine/plasma inulin & $68 \pm 9$ & $39 \pm 8$ & $<0.05$ \\
\hline $\begin{array}{l}\text { Fractional sodium } \\
\text { excretion (\%) }\end{array}$ & $1.3 \pm 0.4$ & $5.0 \pm 1.9$ & NS \\
\hline
\end{tabular}



Figure 3. Percent GFR (postoperative/preoperative) plotted as a function of the suprarenal aortic clamp time.

because of the four patients with the most impaired GFR, in whom postoperative serum creatinine peaked at values $>4 \mathrm{mg}$ / $\mathrm{dl}$ (range $4.2-5.8 \mathrm{mg} / \mathrm{dl}$ ) on the third or fourth postoperative day. In each instance, azotemia resolved spontaneously during the second postoperative week. Judged by a peak serum creatinine level $<2 \mathrm{mg} / \mathrm{dl}$, the remaining 11 patients had a nonazotemic postoperative course. Postoperative azotemia was never observed in the control population in whom preoperative and peak postoperative creatinine levels were identical, averaging $1.2 \pm 0.1 \mathrm{mg} / \mathrm{dl}$.

\section{Transglomerular solute exchange}

The fractional clearance of dextrans in the $r$ interval 22-30 $\AA$ exceeded unity in two of the four patients of the experimental group who became azotemic in the early postoperative period (Fig. 4). No alteration in glomerular transport dynamics could possibly account for more rapid glomerular filtration of larger dextran than smaller inulin molecules by passive forces, a finding which we have observed previously in patients with severe hemodynamically mediated $\operatorname{ARF}(17,30,31)$. A likely explanation for this phenomenon is that tubular impermeability to filtration markers was lost and that small inulin molecules $(r=14 \AA)$ leaked back through necrotic tubule epithelium at a more rapid rate than larger dextran molecules. We therefore excluded these two studies from our theoretical analysis of transcapillary solute exchange (see also Discussion).

The mean dextran fractional clearance profile of the remaining 13 post-TRI patients and that of the control (infrarenal) 


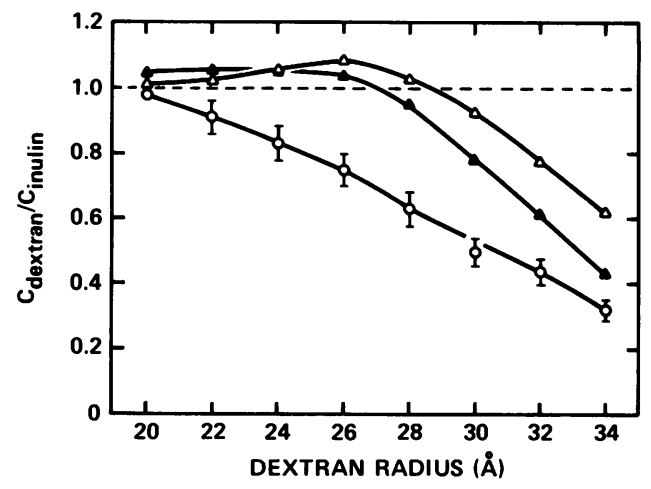

Figure 4. Fractional dextran clearances $\left(\mathrm{C}_{\text {dextran }} / \mathrm{C}_{\text {inulin }}\right)$ in two postTRI patients with azotemia. Note that fractional clearances in the dextran radius interval 22-30 $\AA$ exceed unity. The fractional dextran clearance profile in the control (infrarenal) group is shown for comparison (lower curve, values are mean \pm SEM).

group are compared in Fig. 5. Measurable restriction to dextrans in both populations, indicated by fractional dextran clearances $<1.0$, occurred when $r>22 \AA$. For larger dextrans the fractional clearance declined progressively with increasing radius and approached zero when $r>46 \AA$. In control subjects the values of fractional dextran clearances were similar to those reported by us previously for healthy volunteers (17). For dextran with $r>22 \AA$ in the post-TRI population however, fractional clearances were elevated uniformly above those in control subjects over the entire range of molecular radii examined. This elevation was statistically significant over the dextran radius interval 24 to $40 \AA$ (Fig. 5).

The difference in fractional dextran clearances between the two groups was interpreted in terms of a theoretical model of transcapillary solute exchange based on a hydrodynamic theory of transport of neutral macromolecules through an isoporous membrane (23). Efferent oncotic pressure $\left(\pi_{e}\right)$ in control subjects

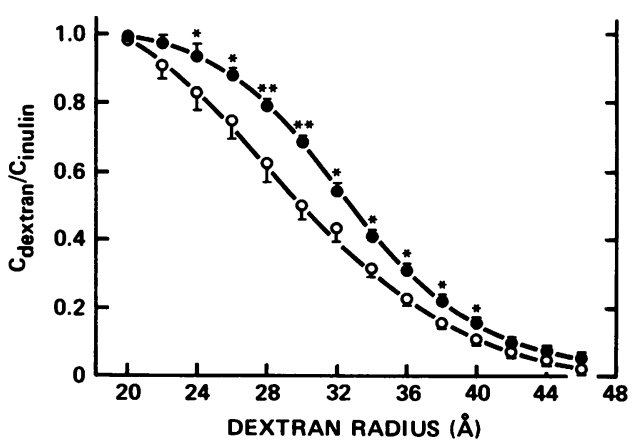

Figure 5. Fractional dextran clearance profiles $\left(C_{\text {dextran }} / C_{\text {inulin }}\right)$ in the control, infrarenal group $(O)$ and in the 13 members of the experimental, suprarenal group not shown in Fig. $4(\bullet)$. Results are expressed as mean \pm SEM. ${ }^{*}, P<0.05 ;{ }^{* *}, P<0.02$. was estimated from knowledge of the filtration fraction and afferent protein concentration to approximate $27 \mathrm{mmHg}(25)$. Accordingly, the lower value assigned to $\Delta \mathrm{P}(30 \mathrm{mmHg}) \mathrm{sim}$ ulates conditions approaching a state of filtration pressure equilibrium $\left(\Delta \mathrm{P}-\pi_{\mathrm{e}} \simeq 3 \mathrm{mmHg}\right)$. The upper assigned value ( $\Delta \mathrm{P}$ $=40 \mathrm{mmHg}$ ), on the other hand, is consistent with marked filtration pressure disequilibrium $\left(\Delta \mathrm{P}-\pi_{\mathrm{e}} \simeq 13 \mathrm{mmHg}\right)$. The corresponding values for $K_{f}$ in control subjects are computed to be 0.1408 or $0.0695 \mathrm{ml} /(\mathrm{s} \cdot \mathrm{mmHg}$ ), respectively (24). From the foregoing estimates of $\Delta P$ and $K_{f}$ together with measured fractional dextran clearances, GFR, RPF, and $\pi_{\mathrm{a}}$, the $\mathrm{r}_{0}$ in control subjects is estimated to be 56.6 or $59.9 \AA$, respectively, depending on the value of $\Delta \mathrm{P}$ chosen (Table VI).

The theoretical effects of isolated reductions in RPF, $\Delta \mathrm{P}$, and $K_{f}$ on the fractional clearance of dextrans are illustrated in Fig. 6. For the sake of simplicity the perturbation of each determinant required to selectively depress the mean GFR in control subjects $(84 \mathrm{ml} / \mathrm{min})$ to that observed in the 13 post-TRI patients illustrated in Fig. $5(50 \mathrm{ml} / \mathrm{min})$ has been analyzed separately. In each analysis the remaining determinants of GFR have been held constant at the values provided for controls in Table VI. For purposes of the analysis it has also been assumed that $\mathbf{r}_{\mathbf{0}}$ did not differ between the two populations.

Using a base value for $\Delta \mathrm{P}$ of $30 \mathrm{mmHg}$, we calculate that either a reduction of renal plasma flow from 397 to $155 \mathrm{ml} /$ min, or of $\Delta \mathrm{P}$ from 30 to $24.6 \mathrm{mmHg}$ could account for the depression of GFR observed in post-TRI relative to control subjects. As shown in Fig. $6 A$ and $B$, each of these selective perturbations is predicted to elevate the mean fractional dextran clearance profile of control subjects to within one standard error of the mean observed in post-TRI patients. By contrast, the isolated reduction of $\mathrm{K}_{\mathrm{f}}$ required to explain the observed hypofiltration $(0.1408$ to $0.0697 \mathrm{ml} / \mathrm{s} \cdot \mathrm{mmHg})$ results in depression of fractional dextran clearances (Fig. $6 \mathrm{C}$ ) and not in their elevation as was observed. Although not shown in Fig. 6, similar trends are observed when a base value of $\Delta P=40 \mathrm{mmHg}$ is used. However, neither the depression of renal plasma flow nor of $\Delta \mathrm{P}$ required to explain the observed hypofiltration (397 $\rightarrow$ $114 \mathrm{ml} / \mathrm{min}$ and $40 \rightarrow 30 \mathrm{mmHg}$, respectively) is adequate to uniformly elevate the fractional clearance profile from control

Table VI. Filtration Data and Calculated Membrane Parameters in Control (Infrarenal) Subjects

\begin{tabular}{lcc}
\hline Assigned $\Delta \mathrm{P}(\mathrm{mmHg})$ & $30^{*}$ & $40^{*}$ \\
RPF $(\mathrm{ml} / \mathrm{min})$ & $397 \ddagger$ & $397 \ddagger$ \\
Afferent protein concentration $(\mathrm{g} / \mathrm{dl})$ & 5.4 & 5.4 \\
GFR $(\mathrm{ml} / \mathrm{min})$ & 84 & 84 \\
Ultrafiltration coefficient $[\mathrm{ml} /(\mathrm{s} \cdot \mathrm{mmH})]$ & 0.1408 & 0.0695 \\
Mean pore radius, $\mathrm{r}_{0}(\tilde{A})$ & 56.6 & 59.9
\end{tabular}

* $\Delta \mathrm{P}$ values are assumed (see text).

$¥$ Renal plasma flow in the control group has been equated with PAH clearance (see Table V). 


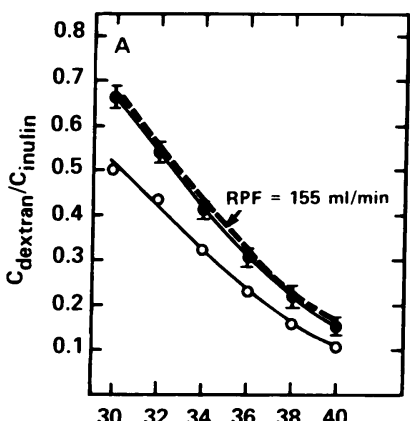

$\begin{array}{llllll}30 & 32 & 34 & 36 & 38 & 40\end{array}$

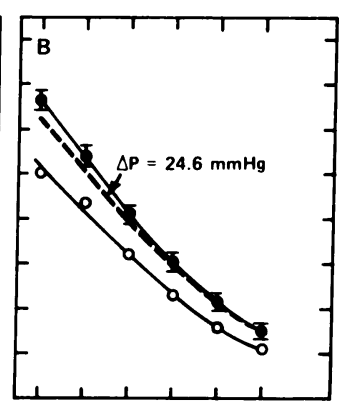

$\begin{array}{lllll}30 & 32 & 36 & 38 & 40\end{array}$ DEXTRAN RADIUS $(\dot{A})$

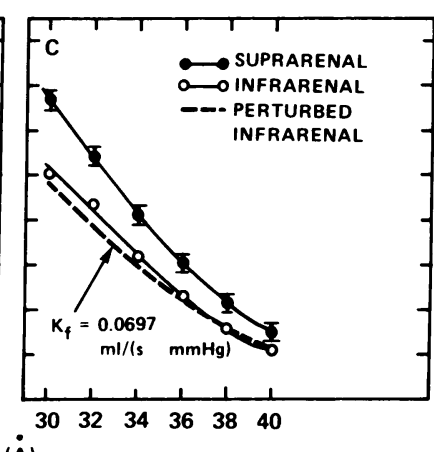

Figure 6. Predicted effects on control (infrarenal) fractional dextran clearances $(O)$ $\left(C_{\text {dextran }} / C_{\text {inulin }}\right)$ of reductions in $\operatorname{RPF}(A)$, $\Delta \mathrm{P}(B)$, and $\mathrm{K}_{f}(C)$. The reduction of each determinant is that calculated to selectively lower GFR from the control value to that observed in post-TRI patients. The base value assigned to $\Delta \mathbf{P}$ $=30 \mathrm{mmHg}$, and the remaining GFR determinants have been held constant at the values listed in Table VI. Reduced $\operatorname{RPF}(A)$ and $\Delta \mathrm{P}(B)$ elevate the control fractional clearance profile (heavy, dashed line) to within one standard error of the mean value in post-TRI patients $(\bullet)$. Reduced $\mathrm{K}_{\mathrm{f}}$ depresses the control values (heavy dashed line, $C$ ). values to within one standard error of the mean observed in post-TRI patients. Similarly, the required reduction of $K_{f}$ (from 0.0695 to $0.0363 \mathrm{ml} / \mathrm{s} \cdot \mathrm{mmHg}$ ) depresses the control fractional dextran clearances even more than under the conditions illustrated in Fig. 6. These calculations suggest that reduction of either renal plasma flow or $\Delta P$ alone, but not of $K_{f}$, can mimic the altered glomerular transcapillary water and solute flux observed in post-TRI patients. It is noteworthy that PAH clearance was higher than the isolated reduction of renal plasma flow required to explain the observed hypofiltration, 200 vs. 155 or $114 \mathrm{ml} / \mathrm{min}$, respectively. Since PAH extraction was very likely reduced, moreover, PAH clearance underestimates true renal plasma flow in this circumstance. It seems likely therefore, that a reduction in $\Delta \mathrm{P}$ alone, or combined with a lesser depression of renal plasma flow than that computed, can be invoked to explain the findings.

\section{Discussion}

Renal injury. The renal injury observed following suprarenal, aortic occlusion in the present study strongly resembles that seen in experimental animals exposed to occlusion of the renal vascular bed of 40-60-min duration. A reversible injury was characterized by glomerular hypofiltration that was disproportionate to a relatively modest reduction in renal blood flow (1, $2,4)$. There was also striking proximal and distal tubular dysfunction which resulted in impaired reabsorption of sodium and water and reduced ability to secrete PAH (3). In keeping with the use of mannitol pretreatment in postischemic experimental ARF, the average rate of urine flow was high, recovery from the renal injury was rapid, and indirect evidence of transtubular inulin backleak was uncommon $(3,12-14)$.

That this renal injury, like its counterpart in experimental animals, may represent an early but self-limited form of ARF is suggested by its striking resemblance to sustained forms of hemodynamically mediated ARF in man. It has become apparent in recent years that sustained, human ARF may manifest as an oliguric or nonoliguric state (31-34). With oliguria, the GFR, as determined by clearance methods, is depressed to $<5 \%$ of normal (35). With nonoliguria, the corresponding measures of GFR are less depressed to a range similar to that found immediately following clamp release in the present study $(30$, 31). By contrast, renal blood flow, as measured by inert gas $(36-38)$ or dye dilution techniques $(39,40)$ in sustained ARF, has been depressed to only $50-67 \%$ of normal, a finding again quite similar to that following TRI. Furthermore, features of proximal and distal tubule dysfunction similar to those demonstrated in the post-TRI population, have also been observed in patients with sustained forms of ARF. Thus, as judged by a lowered PAH extraction ratio, the secretory ability of the proximal tubule in sustained ARF is severely impaired (35), while the reduced ability of the distal tubule to concentrate urine and conserve sodium forms the basis of the laboratory tests by which acute renal failure is commonly diagnosed $(34,41)$. These similarities suggest that had the renal injury induced by mechanical interruption of renal blood flow during aortic surgery been sustained, it would have become manifest as overt, acute renal failure. In attempting to elucidate the pathophysiologic mechanisms responsible for the impairment of GFR that characterizes both conditions, it is useful to consider the relative contribution of those tubular and vascular factors that are of pathogenetic import in experimental, postischemic ARF.

Experimental TRI of 40-60-min duration in the rat is typically followed by a patchy necrosis of tubule cells with partial separation from and denudation of the underlying tubule basement membrane (1). The normal impermeability of tubular epithelium to inulin is frequently lost in the presence of this injury. As a result, only a fraction of inulin microinjected into an early portion of the proximal tubule can be recovered from the urine elaborated by the injured kidney. In general, the duration of TRI and the stage of the tubule injury appear to reflect accurately the presence and magnitude of the inulin backleak. Thus, in the unprotected animal, tubule microperfusion or microinjection have revealed backleak of inulin during the mainte- 
nance phase (1st-7th d) of postischemic $\operatorname{ARF}(3,6)$, and the magnitude of the fraction of injected inulin that leaks back has been correlated with the duration of TRI (1). In contrast, the recovery phase of postischemic ARF appears to coincide with restoration of tubular impermeability to inulin $(6,29)$. In the unprotected animal, recovery from the maintenance phase usually begins in the second week of $\operatorname{ARF}(6,29)$. In the mannitolprotected animal, by contrast, the maintenance phase of ARF is much abbreviated with the result that the onset of recovery is already evident within $24-48 \mathrm{~h}$ following TRI $(13,14)$ and inulin backleak cannot be demonstrated by in vitro tubule microperfusion at this time (3).

The findings in our mannitol-protected patients appear to be in accord with those in experimental ARF. Thus, inulin clearance at $24 \mathrm{~h}$ had already increased twofold over the corresponding value $1-2 \mathrm{~h}$ following TRI, and 11 of the 15 patients failed to manifest azotemia. Judged by the progressive, monotonic decrease below unity of the fractional clearance of dextrans of increasingly large size, 13 of the 15 patients had no evidence of overt transtubular inulin backleak (Fig. 5). In the remaining two patients TRI was protracted beyond $50 \mathrm{~min}$ and, as judged by progressive azotemia for 3-4 d, the maintenance phase of ARF was prolonged, despite prior administration of mannitol. The elevation above unity of the fractional clearance of dextran molecules with radii in the interval 22-30 $\AA$ in these two patients is consistent with transtubular backleak of filtrate (Fig. 4) (17).

Although glomerular permselectivity to dextran molecules in ARF appears to differ from that in control subjects owing to altered glomerular capillary hemodynamics (Fig. 6), no alteration in transport dynamics could possibly account for the more rapid filtration by passive forces of larger dextran ( $r$ $=22-30 \AA)$ than smaller inulin molecules $(r=14 \AA)$. On the other hand, had prolonged TRI rendered the tubule wall in these two patients permeable to inulin and dextran, these normally unreabsorbable polysaccharides would be predicted to leak back passively from the tubule lumen (that is, by ultrafiltration and/or diffusion through the damaged tubule wall). Under these conditions the fractional backleak of dextran (defined as the rate of backleak divided by the GFR) would be expected to be a declining function of the size of the dextran molecules, and to be smaller than the fractional backleak of inulin (17). A disproportionately greater backleak of smaller inulin molecules than larger dextran molecules would appear to account then for an apparent dextran sieving coefficient in excess of unity, based solely on plasma and urinary concentration measurements. Since a tubule epithelium permeable to inulin must also be permeable to the normal constituents of glomerular filtrate, this finding provides compelling evidence for tubule fluid backleak in the two severely azotemic patients illustrated in Fig. 4 (17). Although the evidence is more indirect, the absence of this phenomenon in the remaining 13 patients suggests that overt transtubular backleak of filtrate was not a feature of their milder tubular injury (31). If this inference is correct, then the transglomerular sieving of dextrans can be used to explore the possible role of alterations in the four determinants of glomerular ultrafiltration in lowering GFR following TRI (23).
Determinants of GFR. Judged by PAH clearance and extraction, renal plasma flow averaged $331 \pm 71 \mathrm{ml} / \mathrm{min}$ per 1.73 $\mathrm{m}^{2}$ in the $1 \mathrm{st}$ and $2 \mathrm{nd} \mathrm{h}$ following release of the suprarenal aortic clamp. The simultaneous GFR by contrast averaged only $23 \pm 5 \mathrm{ml} / \mathrm{min}$ per $1.73 \mathrm{~m}^{2}$ with the result that the filtration fraction was depressed to 0.07 . An identical depression of the filtration fraction to 0.07 was observed in the $1 \mathrm{st} \mathrm{h}$ following suprarenal clamp release in 11 patients in whom renal plasma flow was determined with the use of an electromagnetic blood flow meter, and GFR from its product and the renal inulin extraction ratio. These values for the filtration fraction are substantially below the 0.20 seen in the normal kidney (26) and the corresponding value of 0.17 in control subjects (Table III). It follows that the reduction of renal plasma flow observed immediately in the aftermath of TRI is insufficient to explain the observed depression of GFR, and that one or more of the remaining determinants of GFR must have changed simultaneously (24).

The potential contribution of renal underperfusion to the persisting hypofiltration observed $24 \mathrm{~h}$ following TRI is more difficult to ascertain. As with inulin clearance, the PAH clearance in post-TRI patients was only half that of control subjects. Given that PAH extraction was markedly impaired intraoperatively following release of the suprarenal aortic clamp, it is likely that the postoperative PAH clearance underestimated the true renal plasma flow. Theoretical analysis of the enhanced fractional dextran clearances at this time reveals that a selective reduction of renal plasma flow could produce changes in GFR and transglomerular dextran sieving that are qualitatively similar to those actually observed (Fig. 6). However, the hypothetical reduction of renal plasma flow required to account quantitatively for both changes, $155 \mathrm{ml} / \mathrm{min}$, is below the measured PAH clearance, $200 \mathrm{ml} / \mathrm{min}$. Thus, although a reduced renal plasma flow at 24 h could have contributed to the decreased GFR, it cannot be the entire explanation.

$\pi_{\mathrm{a}}$ in this study was measured with a membrane osmometer. It was reduced from preoperative values of $25.6 \pm 0.9$ to $14.6 \pm 0.8$ following clamp release intraoperatively, and $16.4 \pm 0.4 \mathrm{mmHg}$ $24 \mathrm{~h}$ postoperatively. Selective reductions of $\pi_{\mathrm{a}}$ are predicted to increase, not decrease, GFR as was observed (24). Furthermore, and of greater importance, $\pi_{\mathrm{a}}$ was not different between post-TRI patients and control subjects, and therefore cannot explain the differences in GFR. By exclusion, the differences must be attributable to reductions in transcapillary hydraulic pressure difference, or $\mathrm{K}_{\boldsymbol{f}}$, or both.

The $\Delta \mathrm{P}$ represents the imbalance between the integrated hydraulic pressure along the glomerular capillaries and that prevailing in Bowman's space. There is now substantial morphologic evidence that points to tubular obstruction by cell debris, particularly at the level of the pars recta of the proximal tubule, as an important component of experimental ARF following TRI $(1,14)$. A rise in pressure upstream in Bowman's space due to tubular obstruction could lower $\Delta P$ without a concomitant fall in capillary hydraulic pressure $(4,5)$. Alternately, impaired reabsorption in the proximal tubule, because of injury to the tubule cells (3), could cause afferent vasoconstriction via the 
tubuloglomerular feedback mechanism, thereby lowering glomerular capillary hydraulic pressure, and hence $\Delta \mathrm{P}$. The indirect methods used in the present study cannot distinguish between these two potential mechanisms of proximal tubule injury whereby $\Delta \mathrm{P}$ might become lowered following TRI. Severe impairment of PAH extraction, however, points to injury of the proximal tubule.

Two other findings are consistent with the possibility that glomerular hypofiltration was caused, at least in part, by a fall in $\Delta \mathrm{P}$. Anuria for $20 \mathrm{~min}$ or longer was observed in six patients immediately following TRI. The absence of inulin extraction during five of these anuric episodes is consistent with cessation of glomerular filtration due to tubular obstruction with a severe reduction of $\Delta P(4,5)$. Profound reduction of $K_{f}$, however, could also explain this finding (2). Similarly, continued formation of filtrate with backleak of inulin into the peritubular capillaries, and subsequent return to the renal vein, could likewise account for the paradox of negligible renal inulin extraction in the face of adequate renal perfusion during anuria. The analysis of the relation of GFR to transglomerular dextran flux also provides indirect evidence that reduction of $\Delta \mathrm{P}$ may be implicated in the persisting glomerular hypofiltration observed $24 \mathrm{~h}$ after TRI. Of the perturbations of GFR determinants examined by our theoretical analysis, only selective reduction of $\Delta \mathrm{P}$ accounts for both the observed reduction in GFR and the elevation of transglomerular dextran transport (Fig. 6).

Because of the heterogeneity of the injury among nephrons and the difficulty in collecting adequate samples of proximal tubular fluid, $K_{f}$ has been difficult to evaluate in vivo in experimental animals with postischemic ARF. A recent attempt to measure this parameter suggests, however, that it is substantially reduced $18 \mathrm{~h}$ following TRI in the $\operatorname{dog}(42)$. Ultrastructural changes in the glomerular capillary wall at this time included spreading and flattening of epithelial podocyte bodies with loss of discrete foot processes and reduced endothelial fenestrations. Such changes are consistent with a loss of surface area for filtration, and are presumed to be the morphological counterpart of a reduction in $\mathrm{K}_{f}(42-44)$. In a study of glomerular ultrastructure at the time of transplantation of human kidneys subjected to previous warm ischemia, however, Solez and co-workers (43) observed a marked loss of discrete foot processes only in those kidneys in which prolonged ARF subsequently became manifest. As stated previously, 11 of the post-TRI patients in the present study never developed azotemia, while azotemia in the remainder was transient and relatively brief. From the findings of Solez et al. (43) it therefore seems unlikely that glomerular ultrastructure was markedly altered in our patients. In accord with this supposition, our analysis suggests that a selective reduction of $K_{f}$ cannot explain the observed findings. Indeed, an isolated reduction of $\mathbf{K}_{\boldsymbol{f}}$ sufficient to account for the reduced GFR would lower, not elevate, the fractional dextran clearances, as was observed (Fig. 6). Thus, if $K_{f}$ was in fact reduced $24 \mathrm{~h}$ following TRI, such reduction must have been so minor that its effect on transglomerular sieving of dextrans was more than offset by the proportionately larger reductions in renal plasma flow or $\Delta \mathrm{P}$.
Our analysis of transcapillary solute exchange provides a possible but not exclusive explanation for the increased transglomerular passage of dextrans in post-TRI patients. It assumes that the mean radius of functional pores perforating the glomerular capillary wall was not altered by TRI. Because of technical difficulties referred to earlier, no micropuncture data are available which characterize the sieving behavior of the glomerulus in postischemic ARF. Thus, our assumption cannot be confirmed. Certainly an increase in pore radius alone cannot explain the enhanced transglomerular dextran transport (23). Larger pores would be associated with less resistance to water flow at a given ultrafiltration pressure, whence GFR would be predicted to increase and not to decrease, as was observed. A modest increase in pore radius combined with other changes in the determinants that lower GFR cannot, however, be excluded. That pore radius is unlikely to have increased is suggested by the ultrastructural changes in the epithelial and endothelial layers of the glomerular capillary wall to which we have already alluded (42-44). Such changes occur in an even more marked form in the glomerulopathy induced by aminonucleoside, yet mean pore radius in this disorder is not different from normal (45). The same is true of the idiopathic nephrotic syndrome in man, in which similar ultrastructural changes have also been associated with an unchanged value for mean pore radius (46, 47). Based on this indirect evidence, we submit that a significant enlargement of pore size in our post-TRI population did not occur and that it is reasonable to assume that the mean pore radius was equivalent to that in the controls.

If additional hemodynamic or nephrotoxic insults eventuated, it would not be difficult to envisage conversion of the renal injury induced by TRI in the present study into a severe and protracted form of ARF. In such an event, the patient would become susceptible to the high mortality that attends postoperative ARF complicating aortic surgery $(7,8)$. Species differences and the varying and highly contrived nature of the ischemic insult used to induce ARF in experimental animals require that caution be exercised when extrapolating pathophysiologic findings to human ARF. Nevertheless, the findings in the present study suggest that the pathophysiology of the renal injury following TRI in man is similar to that in analogous experimental animal models. Therefore, it is noteworthy that postischemic ARF in experimental animals can be prevented or limited by protective agents other than mannitol $(13,48$, 49). We propose that these alternate therapeutic modalities be evaluated in man. It would seem that additional measures are warranted to protect against the ravages of ARF when surgical repair of the aorta requires TRI of $50 \mathrm{~min}$ or longer (Fig. 3), or when such surgery is undertaken to resect a ruptured aneurysm in a hemodynamically compromised patient.

\section{Acknowledgment}

This study was supported by National Institutes of Health grant AM29985. 


\section{References}

1. Donohoe, J. F., M. A. Venkatachalam, D. B. Bernard, and N. G. Levinsky. 1978. Tubular leakage and obstruction after renal ischemia: structural functional correlations. Kidney Int. 13:208-222.

2. Cronin, R. E., A. B. Erickson, A. DeTorrente, K. M. McDonald, and R. W. Schrier. 1978. Norepinephrine-induced acute renal failure: a reversible ischemic model of acute renal failure. Kidney Int. 14:187190.

3. Hanley, M. J., and K. Davidson. 1981. Prior mannitol and furosemide infusion in a model of ischemic acute renal failure. Am. J. Physiol. 241:F556-F564.

4. Arendhorst, W. J., W. F. Finn, C. W. Gottschalk, and H. K. Lucas. 1976. Micropuncture study of acute renal failure following temporary renal ischemia in the rat. Kidney Int. 10:S100-S105.

5. Tanner, G. A., and S. Sophasan. 1976. Kidney pressures after temporary renal artery occlusion in the rat. Am. J. Physiol. 230:11731181.

6. Eisenbach, G. M., and M. Steinhausen. 1973. Micropuncture studies after temporary ischemia of rat kidneys. Pfluegers Arch. 343:1125.

7. Abbott, W. M. 1980. Renal Failure Complicating Vascular Surgery. In Complications in Vascular Surgery. V. M. Bernhard and J. B. Tanner, editors. Grune \& Stratton, Inc., New York. 363-377.

8. McCombs, P. R., and B. Roberts. 1979. Acute renal failure following resection of abdominal aortic aneurysm. Surg. Gynecol. Obstet. 148:175-178.

9. Luft, F. C., R. J. Hamburger, J. K. Dyer, J. J. Szwed, and S. A. Kleit. 1978. Acute renal failure following operation for aortic aneurysm. Surg. Gynecol. Obstet. 141:374-377.

10. Kwaan, J. H. M., and J. E. Connolly. 1980. Renal failure complicating aortoiliofemoral reconstructive procedure. Am. Surg. 46:246297.

11. Barry, M. K., A. Cohen, J. P. Knochel, T. J. Whelan, Jr., W. R. Beisel, C. A. Vargas, and P. C. LeBlanc, Jr. 1961. Mannitol Infusion. II. The prevention of acute functional renal failure during resection of an aneurysm of the abdominal aorta. N. Engl. J. Med. 264:967-971.

12. Burke, T. J., R. E. Cronin, K. L. Duchin, L. N. Peterson, and R. W. Schrier. 1980. Ischemia and tubule obstruction during acute renal failure in dogs: mannitol in protection. Am. J. Physiol. 238:F305-F314.

13. Patak, R. V., S. Z. Fadem, M. D. Lifschitz, and J. H. Stein. 1979. Study of factors which modify the development of norepinephrineinduced acute renal failure in the dog. Kidney Int. 15:227-237.

14. Cronin, R. E., A. DeTorrente, P. D. Miller, R. E. Bulger, T. J. Burke, and R. W. Schrier. 1978. Pathogenic mechanisms in early norepinephrine-induced acute renal failure: functional and histological correlates of protection. Kidney Int. 14:115-125.

15. Fjeldbo, W., and T. A. Stamey. 1968. Adapted method for determination of inulin in serum and urine with an autoanalyzer. J. Lab. Clin. Med. 72:353-358.

16. Harvey, R. B., and A. J. Brothers. 1962. Renal extraction of para-amino-hippurate and creatinine measured by continuous in vivo sampling of arterial and renal vein blood. Ann. NY Acad. Sci. 102:4654.

17. Myers, B. D., F. Chui, M. Hilberman, and A. Michaels. 1979. Transtubular leakage of glomerular filtrate in human acute renal failure. Am. J. Physiol. F319-F325.

18. Laurent, T. C., and J. Killander. 1964. A theory of gel filtration and its experimental verification. J. Chromatogr. 14:317-330.
19. Granath, K. A., and B. E. Kvist. 1967. Molecular weight distribution analysis of gel chromatography on Sephadex. J. Chromatogr. 28:69-81.

20. Scott, T. A., and E. H. Melvin. 1953. Determination of dextran with anthrone. Anal. Chem. 25:1656-1661.

21. Fabing, D. L., and G. Erthinghausen. 1971. Automated reaction rate for determination of serum creatinine with the centrifichem. Clin. Chem. 17:696-702.

22. Chang, R. L. S., I. F. Ueki, J. L. Troy, W. M. Deen, C. R. Robertson, and B. M. Brenner. 1975. Permselectivity of the glomerular capillary wall to macromolecules. II. Experimental studies in rats using neutral dextran. Biophys. J. 15:887-895.

23. Chang, R. L. S., C. R. Robertson, W. M. Deen, and B. M. Brenner. 1975. Permselectivity of the glomerular capillary wall to macromolecules. I. Theoretical considerations. Biophys. J. 15:861-886.

24. Deen, W. M., C. R. Robertson, and B. M. Brenner. 1972. A model of glomerular ultrafiltration in the rat. Am. J. Physiol. 223:11781183.

25. Myers, B. D., M. Hilberman, B. J. Carrie, R. J. Spencer, E. B. Stinson, and C. R. Robertson. 1981. Dynamics of glomerular ultrafiltration following open-heart surgery. Kidney Int. 20:366-374.

26. Davies, D. F., and N. W. Shock. 1950. Age changes in glomerular filtration rate, effective renal plasma flow, and tubular excretory capacity in adult males. J. Clin. Invest. 29:496-507.

27. Porter, G., F. Kloster, R. Herr, A. Starr, H. Griswold, J. Kimsey, and $H$. Lenertz. 1966. Relationship between alterations in renal hemodynamics during cardiopulmonary bypass and postoperative renal function. Circulation. 34:1005-1021.

28. Tukey, J. W. 1977. Exploratory Data Analysis. Addison-Wesley Publishing Co., Reading, MA, Chapt. 7-16.

29. Finn, W. F., and A. L. Chevalier. 1979. Recovery from postischemic acute renal failure in the rat. Kidney Int. 16:113-123.

30. Myers, B. D., B. J. Carrie, R. R. Yee, M. Hilberman, and A. S. Michaels. 1980. Pathophysiology of hemodynamically mediated acute renal failure in man. Kidney Int. 18:495-504.

31. Myers, B. D., M. Hilberman, R. J. Spencer, and R. L. Jamison 1982. Glomerular and tubular function in non-oliguric acute renal failure. Am. J. Med. 72:642-649.

32. Vertel, R. M., and J. P. Knochel. 1967. Non-oliguric acute renal failure. J. Am. Med. Assoc. 200:598-602.

33. Myers, C., D. M. Roxe, and J. E. Hano. 1977. The clinical course of nonoliguric acute renal failure. Cardiovasc. Med. 2:669-672.

34. Miller, T. R., R. J. Anderson, and S. L. Linas. 1978. Urinary diagnostic indices in acute renal failure. A prospective study. Ann. Intern. Med. 89:47-50.

35. Bull, G. M., A. M. Joekes, and K. G. Lowe. 1950. Renal function studies in acute tubular necrosis. Clin. Sci. 9:379-404.

36. Munck, O. 1958. Renal circulation in acute renal failure. Blackwell Scientific Publications, Oxford. 22-37.

37. Hollenberg, N., M. Epstein, R. Rosen, R. I. Basch, D. E. Oken, and J. P. Merrill. 1968. Acute oliguric renal failure in man: evidence for preferential renal cortical ischemia. Medicine (Baltimore). 47:455474.

38. Epstein, M., N. S. Schneider, and B. Befeler. 1975. Effect of intrarenal furosemide on renal function and intrarenal hemodynamics in acute renal failure. Am. J. Med. 58:510-516.

39. Reubi, F. C., C. Vorburger, and J. Tuckman. 1973. Renal distribution volumes of indocyanine green $\left({ }^{51} \mathrm{Cr}\right)$ EDTA and ${ }^{24} \mathrm{Na}$ in man during acute renal failure after shock. J. Clin. Invest. 52:223-235. 
40. Reubi, F. C., and C. Vorburger. 1976. Renal hemodynamics in acute renal failure after shock in man. Kidney Int. 10:S137-S143.

41. Harrington, J. T., and J. J. Cohen. 1975. Acute oliguria. N. Engl. J. Med. 292:89-91.

42. Williams, R. H., C. E. Thomas, L. G. Navar, and A. P. Evan 1981. Hemodynamic and single nephron function during the maintenance phase of ischemic acute renal failure in the dog. Kidney Int. 19:503-515.

43. Solez, K., L. C. Racusen, and A. Whelton. 1981. Glomerular epithelial cell changes in early postischemic acute renal failure in rabbits and man. Am. J. Pathol. 103:163-173.

44. Barnes, J. L., R. W. Osgood, H. J. Reinecke, and J. H. Stein. 1981. Glomerular alterations in an ischemic model of acute renal failure. Lab. Invest. 45:378-386.

45. Bohrer, M. P., C. Baylis, and C. R. Robertson. 1977. Mechanism of the puromycin-induced defects in the transglomerular passage of water and macromolecules. J. Clin. Invest. 69:152-161.

46. Bridges, C. R., B. D. Myers, B. M. Brenner, and W. M. Deen. 1982. Glomerular charge alterations in human minimal change nephropathy. Kidney Int. 22:677-684.

47. Winetz, J. A., C. R. Robertson, H. V. Golbetz, B. J. Carrie, W. R. Salyer, and B. D. Myers. 1981. The nature of glomerular injury in minimal change and focal sclerosing glomerulopathies. Am. J. Kid. Dis. 1:91-98.

48. DeTorrente, A., P. D. Miller, R. E. Cronin, P. E. Paulsen, A. L. Erickson, and R. W. Schrier. Effects of furosemide and acetylcholine in norepinephrine-induced acute renal failure. Am. J. Physiol. 235:F131F136.

49. Mauk, R. H., R. V. Patak, S. Z. Fadem, M. D. Lifschitz, and J. H. Stein. 1977. Effect of prostaglandin $E$ administration in a nephrotoxic and vasoconstrictor model of acute renal failure. Kidney Int. 12:122-130. 